\title{
Everyday Creativity in Times of COVID-19: A Qualitative Study from Argentina*
}

\author{
Romina Cecilia Elisondo \\ María Fernanda Melgar \\ University of Río Cuarto, Argentina \\ National Council of Scientific and Technical Research of Argentina \\ University of Río Cuarto, Argentina \\ E-mail address: relisondo@gmail.com \\ E-mail address: fernandamelgar@gmail.com
}

\section{ARTICLE INFO}

\section{Keywords:}

Everyday creativity

COVID-19

Emotions

Motivation

Isolation

Resilience

\section{Article history:}

Received 05 September 2020

Received in revised form 22 November 2020

Accepted 13 December 2020

ISSN: 2354-0036

DOI: $10.2478 /$ ctra-2020-0013

\section{A B S TR A C T}

The main objective was to study creative processes in isolation by COVID-19. We analyzed, from the participants' perspective, activities, emotions, and motivations linked to everyday creativity in quarantine. The study was carried out between March 27 and April 12, 2020, in Argentina, during Social and Preventive Isolation by COVID-19. The sample included 302 men and women who lived in different provinces in Argentina: Córdoba, Buenos Aires, San Luis, La Pam$\mathrm{pa}$, and San Juan. The participants' ages ranged from 18 to 77 years. All participants answered an online questionnaire with open-ended questions. We analyzed textual data, images, and videos with ATLAS.TI8. From qualitative analyses, we elaborated four categories: With things we had at home: creative activities in isolation; Alone, but not so alone; Being and feeling in isolation; Creativity, motivations, and quarantine. The results indicated that most participants carried out various creative activities in quarantine. These activities generated positive emotions and allowed to face negative emotions related to the pandemic. The motivations had been varied, although reasons related to enjoyment, coping, and sharing with other people are predominant. Apparent paradoxes arise from the analysis of everyday creativity in the time of COVID-19. The knowledge produced in the study can contribute to formulate psychological interventions and public health policies during a pandemic.

\footnotetext{
"This work was supported by the University of Río Cuarto and National Council of Scientific and Technical Research of Argentina (PIP 11220130100474).
} 


\section{INTRODUCTION}

Since December 2019, when the first case of COVID-19 was reported in China, the world has changed. According to the World Health Organization (2020), the coronavirus disease pandemic has effectively transformed everyday life. A localized COVID-19 outbreak turned into a global pandemic with three defining characteristics: scale (the disease has spread rapidly and has overwhelmed even the most resistant health systems), severity (20\% of cases are severe or critical, with a gross case-fatality rate exceeding $3 \%$ ), and socioeconomic disturbance (disruptions to health and social care systems, measures taken to control transmission have socio-economic consequences). The rapid spread of the virus has prompted different measures by governments. In addition to sanitary and hygiene measures, social isolation and restriction of movement are the main actions. On March 20, 2020, Mandatory and Preventive Social Isolation was declared in Argentina (Official Gazette of the Argentine Republic, 2020). During the period of isolation, people must remain at home and abstain from going to work; they can only travel to stock up on cleaning supplies, medicines and food.

Isolation measures have shaped new ways of life in many countries. Numerous studies indicate problems related to mental and community health in contexts of social isolation by COVID-19. Research indicates increased stress, anxiety, depressive symptoms, insomnia, denial, anger, and fear of COVID-19, as well as transformations in daily life that the pandemic has caused (Brooks et al. 2020; Li, Wan, Xue, Zhao, \& Zhu, 2020; Shigemura, Ursano, Morganstein, Kurosawa \& Benedek, 2020; Stankovska, Memedi, \& Dimitrovski, 2020; Torales, O'Higgins, Castaldelli-Maia, \& Ventriglio, 2020; Wang et al. 2020).

Johnson, Saletti-Cuesta, and Tumas (2020) carried out a study on subjective and emotional effects in the first stage of the pandemic in Argentina. They noted an impact on mental health, expressed in feelings of fear, uncertainty and anguish. However, they also reveal other aspects valued as positive for society, such as a sense of responsibility and care, as well as interdependence of people and the possibility of reflection both on themselves and on society. The results show a broad view of the social and political system, the respondents perceive possible changes that are linked to their position in the social structure. Gender and social differences indicate inequality of cultural and material resources in the context of the health crisis and differential impact of the pandemic on mental health.

Without ignoring the negative impacts of the pandemic, in this study we are interested in focusing our lens on the potential of isolation in the context of everyday creativity. In this paper, we try to focus on a creative and resilient view of isolation in a pandemic. We agreed with Vinkers et al. (2020) on the need to focus on resilience during the current pandemic. According to the authors, resilience is essential to cope with stress and to 
maintain balance at the individual and social level. The authors propose promoting social connection, routine planning, self-care, physical exercise, and good nutrition. They also point out that it is important to help people feel that they have some control over everyday situations. Forgeard's (2013) study indicated relationships between post-traumatic growth, anxiety and creativity. After traumatic situations, people exhibited greater creativity, made changes in interpersonal relationships and opened up new life possibilities.

Specifically, the aim of the present study is to analyze creative processes that a group of adults develops during isolation. We conducted a qualitative study with the purpose of understanding meanings constructed by the subjects regarding their creative actions, motivations, and emotions linked to the development of creativity in quarantine. The study was carried out between March 27 and April 12 in phase 1 (Strict Isolation) and phase 2 (Administered Isolation). Strict Isolation authorizes only the movement of people who work in activities considered essential. In Administered Isolation, the sectors related to the sale of construction materials, mining, nuclear and forestry industries, manufacture of agricultural machinery, foreign trade and cooperatives were authorized (Official Gazette of the Argentine Republic, 2020). We emphasize the importance of qualitative studies as designs that allow us to understand meanings constructed by the participants. Likewise, we highlight the importance of studying creative processes in geographic contexts far from the hegemonic centers of creativity (Glăveanu et al. 2019) and the development of new epistemologies in the field of research (Glăveanu \& Sierra, 2015). We also highlight that the knowledge produced from the study of creative processes in quarantine can contribute to public health planning policies.

\section{Theoretical and Epistemological Assumptions}

The study is supported by theoretical and epistemological perspectives that underline the importance of investigating creative processes in everyday contexts. Recently in the Creativity Manifesto, specialists have pointed out that creativity is materialized from actions in different contexts and situations; it is largely constituted by the situation and the domain through which it is expressed. Likewise, specialists point out that creativity is relevant for both subjects and societies; it is present by changing the ways in which people relate to the world, allowing them to be more flexible and open to the new. Creativity is also defined as a socio-cultural and relational process; it always involves other people and is mediated by the language and cultural practices of each community (Glăveanu et al. 2019).

Considering the contributions of Glăveanu and Sierra (2015), this study recovers considerations of the Epistemologies of the South: creativity is a practice that contributes to the daily existence and sustainable livelihood of communities around the world. The authors propose theories of creativity that connect mind and body, person and context, rec- 
ognizing the value and diversity of local practices and the multiple manifestations of originality and novelty. From these perspectives, creative processes are collaborative, supportive, and complementary; evaluations of creative products should also address multiple perspectives. Southern epistemologies propose pluricultivation of the mind to the creation of multiple possible worlds to develop sustainable societies oriented towards Living Well to build balanced relations with the natural environment and other communities. The authors also stress the need to consider political and moral dimensions in the study of creativity.

The study focuses on little-c creativity (Kaufman \& Beghetto, 2009), that is, on everyday manifestations of creativity in different daily situations. Little-c creativity includes artistic, social, and cultural activities carried out by amateurs who do not intend to professionally engage in these fields. They are activities that are carried out by intrinsic motivation and promote well-being and health of people (Richards, 2010). We also rely on a dynamic perspective and define creativity as potential for originality and effectiveness. A potential acts in different ways at various moments and components of creativity. From sociocultural perspectives, potentials are developed from interactions between subjects and contexts, depending on available resources, experiences, and cultural practices (Corazza \& Glăveanu, 2020).

\section{Everyday Creativity, Emotions and Health}

In the present investigation, we also define creativity as an organic phenomenon, indispensable to produce the necessary radical changes in our behaviors and allow new forms of long-lasting well-being (Corazza, 2017). Numerous studies indicate relationships between creativity, positive emotions and health. Silvia et al. (2014) observed that people expressed feeling happier and more active when they carried out some creative activities. Corner and Silvia (2015) find relationships between highly activated positive emotions (enthusiasm, energy, etc.) and daily creativity activities. Karwowski, Lebuda, Szumski, and Firkowska-Mankiewicz (2017) conducted two studies examining the dynamics and predictors of creative activity in adults. In both studies, they found that positive emotions are the most consistent predictors of creativity. The results indicate that everyday creative behavior is a positive emotional experience. Conner, DeYoung, and Silvia (2018) studied relationships between creative days, creative activity, affect, and psychological well-being. The findings indicate that everyday creativity is a means of cultivating positive psychological functioning. In a recent paper (Elisondo \& Vargas, 2019), we analyzed manifestations of everyday creativity from the perspective of a group of women. The results show that the development of daily creative activities is related to well-being and positive emotions (pleasure, passion, desire, satisfaction, self-fulfillment, and personal expression). Fancourt, Garnett and Müllensiefen (2020) analyzed the role of artistic creative activities in the 
regulation of emotions. The results indicated that women make more use of creative activities to regulate their emotions than men. Commitment to and enjoyment of creative activities are positively linked to the ability to use these activities to regulate emotions.

Benedek, Bruckdorfer and Jauk (2019) presented two studies, in which they analyzed nine relevant motives for everyday creativity: enjoyment, expression, challenge, coping, social, prosocial, recognition, material, and duty. The researchers found that enjoyment was the strongest motive for everyday creativity. Relevance of motives differed between creative domains: visual arts, literature, and music were more strongly influenced by motives of expression and coping. Crafts and creative cooking were more motivated by prosocial and recognition motives. Tan, Lau, Kung and Kailsan (2019) analyzed the mediating role of motivation and commitment in the relationships between creativity and openness to experience. The results showed that individuals who scored high on opening reported high intrinsic motivation. High motivation improved participation in activities related to creativity, which in turn improved self-valued creativity. The findings highlight the importance of intrinsic motivation and commitment in creative processes.

In summary, the present study is based on current research of everyday creativity and in the evidences observed regarding the relationships between creativity, positive emotions and health. Based on this background, we propose to analyze creative processes, emotions and motivations in isolation by COVID-19. We consider that this topic is relevant to understand the potentialities of creative behaviors in pandemic and postpandemic time. The new normalities demand creative actions and projects.

\section{METHOD}

\section{Participants}

Three hundred and two ( $\mathrm{N}=302)$ women $(75 \%)$ and men $(25 \%)$ participated in the study. The participants were selected by means of convenience, non-probability sampling with consideration of the diversity of ages, education levels, geographical areas of residence, and occupations. The respondents were 18-77 years of age $(M=39.07$ years old, $S D=12.29)$ : 18-30 years old (67\%), 31-50 years old (24\%), and over 51 years old (9\%). The participants lived in different provinces in Argentina: Córdoba (84\%), Buenos Aires (8\%), San Luis (5\%), La Pampa (2\%), and San Juan (1\%). All participants spoke Spanish and had an average socioeconomic level. The sample included individuals with different education levels: 4 (1\%) completed primary school, 206 (68\%) completed high school and 92 (31\%) completed university studies. The sample included people with different occupations: 144 (48\%) students; 51 (17\%) independent professionals, 40 (13\%) administrative or commercial employees, $33(12 \%)$ teachers, 15 (5\%) housewives, 7 (2\%) domestic or rural employees, 7 (2\%) retired and $5(1 \%)$ unemployed. 


\section{Measures}

All participants answered an online questionnaire with open questions about sociodemographic data (sex, age, schooling, place of residence, occupation), creative activities, emotions, and motivations during isolation. We also included questions regarding particularities of creative activities, specifically; we asked whether they carried out those same activities in contexts of non-isolation and how they perceived the current contexts in relation to creative processes. We also requested that participants provide images and videos of the creative activities.

\section{Procedures and Analysis}

The participants gave their consent to participate in this research and publish the data. The research was designed according to the American Psychological Association's ethical principles (American Psychological Association, 2017). We used the ATLAS.ti 8 software for the qualitative analysis of textual and audiovisual data. We performed open coding to build categories and word clouds to systematize the data. We triangulated analyses by different researchers and built strategies of communicative validity with the participants (interviews and focus groups about results and constructed analyses).

\section{RESULTS}

\section{With Things we Had at Home: Creative Activities in Isolation}

Participants reported having performed various creative activities in isolation. Only three participants said they had not done anything creative in quarantine. Most $(N=180)$ refer to activities related to cooking, as clearly observed in the word cloud (See Figure 1). The results indicate creative activities related to the preparation of original recipes, meals that have never been prepared before, and dishes with the ingredients that they had at home. Participants consider these activities as creative because they involve new and original products for themselves and for others. Participants also highlight the value of cooking as a space to connect with others, in some cases in the preparation of food and in others, in the act of sharing it at the family table. Current studies (Beghetto, Kaufman, \& Hatcher, 2016; McCabe \& de Waal Malefyt, 2015) indicate that cooking is an activity conducive to the development of creative processes, as it allows original combinations and generating novel products in certain sociocultural contexts.

Development of creativity in the kitchen also permits solving problems related to the shortage of ingredients and the need to feed other people. Many claim to have made basic foods, such as bread, that they had never made before. In connection with this, interest in cultivating and creating vegetable gardens at home appears in several participants $(\mathrm{N}=15)$; activities that they had never performed before. 


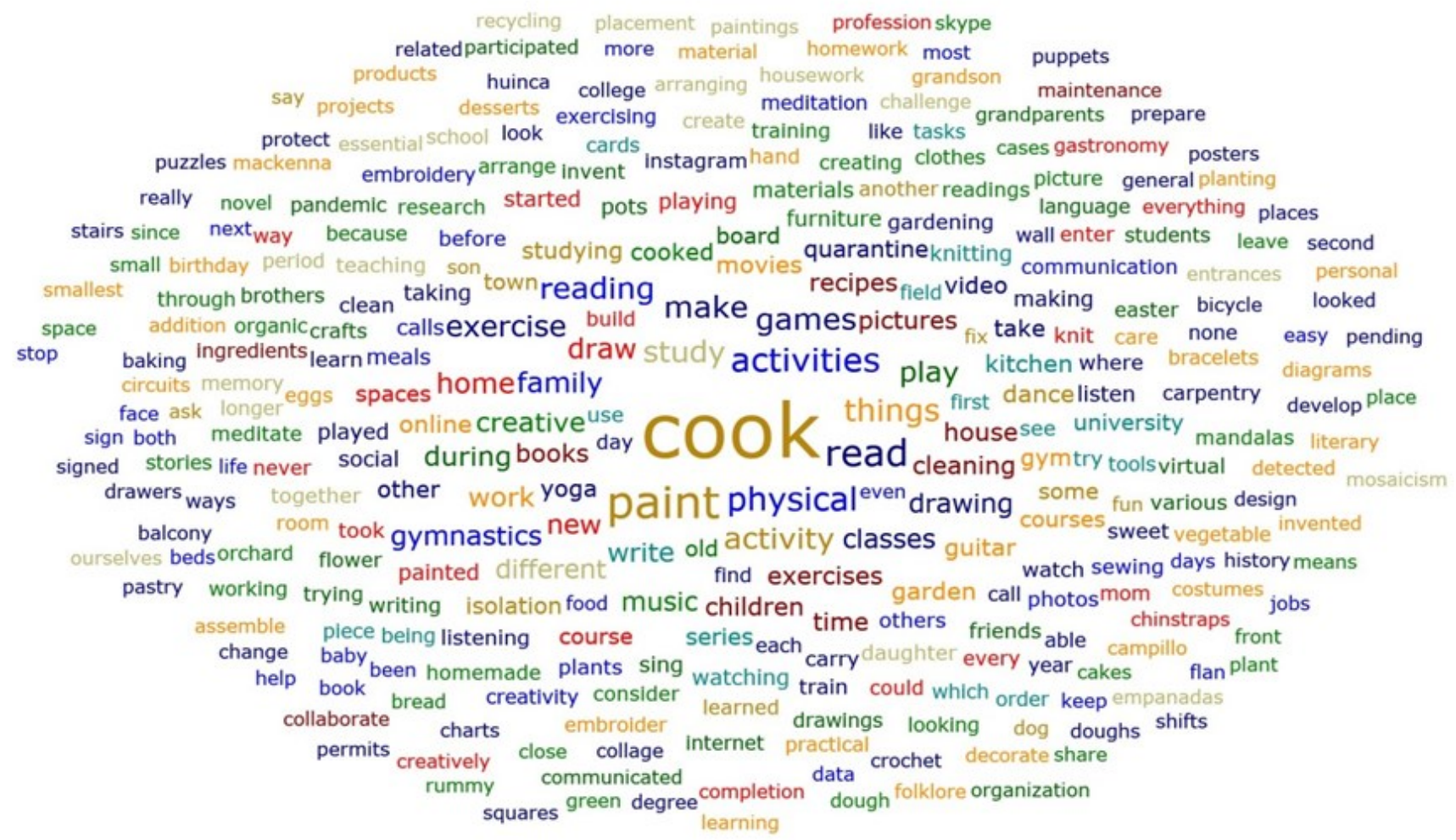

Figure 1. Creative Activities in Isolation. Word Cloud by ATLAS.ti 8

The participants showed a notorious interest in producing food at home, especially in vegetable gardens (See Figure 2). Creativity, in the particular context we analyze, seems to contribute to generation of healthy and sustainable changes, forging creative forms of food and production. One might wonder whether these changes will be sustained over time after isolation and what may be the impacts of the experiences lived in quarantine on changing habits. Gfeller (2019) analyzes creative processes in the construction of new forms of food production and consumption. The author indicates relationships between everyday creativity processes and new forms of feeding and food production. According to the author, transformations in the ways of producing and consuming food can be considered creative processes as they imply ruptures in traditional ways and promote new ways of connecting with nature. Likewise, we find relationships between these sustainable creative practices and the assumptions of the Epistemologies of the South in the study of creativity (Sierra \& Glăveanu, 2015). 

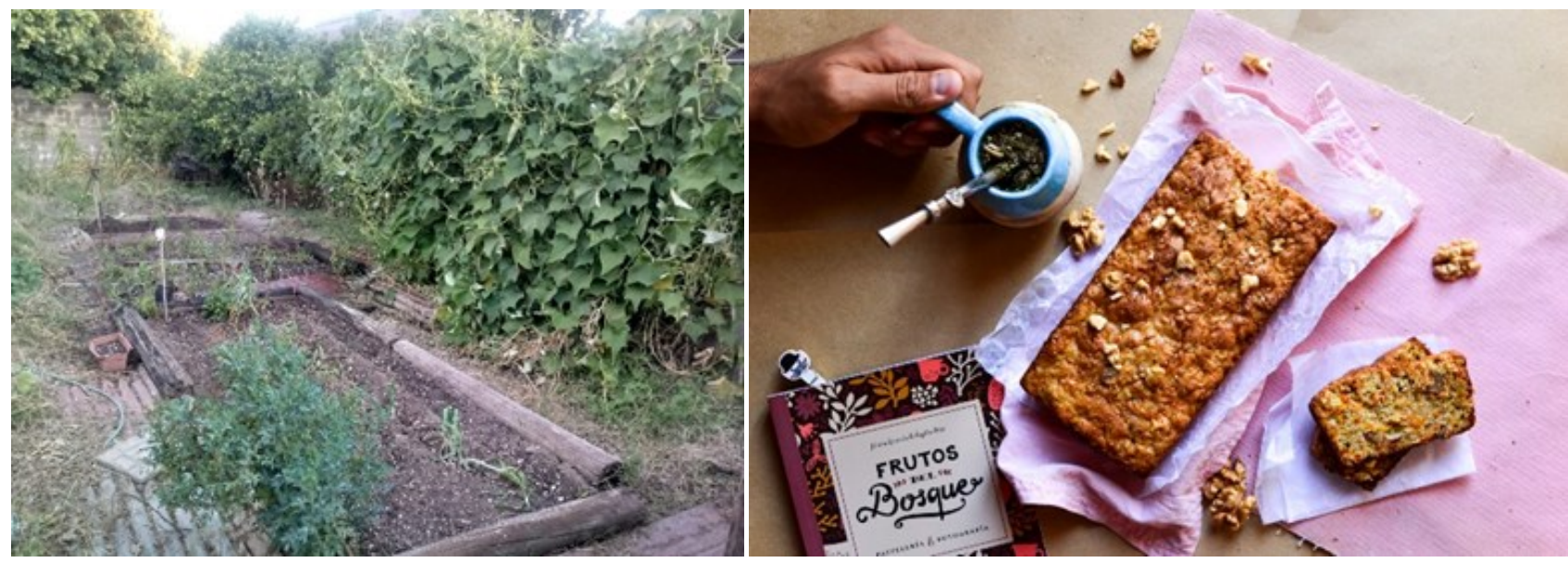

Figure 2. From the Ground to the Table. Source: Images Shared by Participants

Many participants $(N=120)$ referred to creative activities related to handicrafts (crafts, embroidery, textile design). They have also highlighted as a particularity that they had to carry out these activities with the resources available in the home (See Figure 3). Numerous participants $(N=110)$ have developed creative activities in the visual arts (drawing, painting, photography, etc.). The design of interior and exterior spaces was also an activity carried out by several participants $(N=45)$. Some participants $(N=43)$ performed musical activities during social isolation (instrument playing, musical composition, etc.). Dance and original choreography design are activities carried out by several of the people surveyed $(\mathrm{N}=34)$. Meditation, yoga and spaces of self-knowledge have also been activities mentioned by some participants.
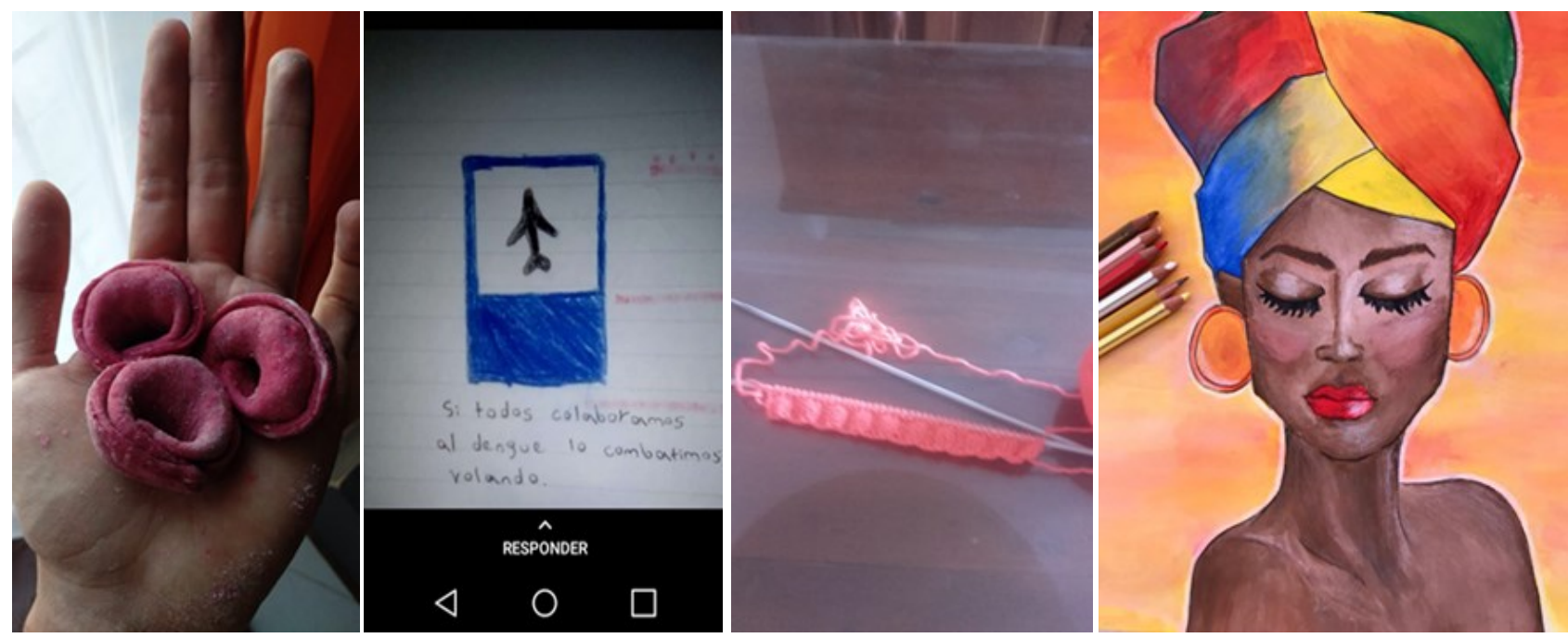

Figure 3. Imagine, Create, Challenge. Source: Images sent by Participants

Various participants $(\mathrm{N}=59)$ report having performed physical activities during isolation. They consider these activities creative since they had to create spaces and objects where they could develop them. Also, some participants express having created new ways of training and sharing these activities with their family. Participants identify creative 
processes in creating the conditions necessary to perform physical activities and in designing those activities.

The space restrictions for physical activity seem to promote divergent processes of creating objects and alternatives. Creative activities related to caring for other people stand out among participants' responses. In isolated contexts, care appears as an important activity, especially in the case of people with dependent children. Participants report having created recreational and family interaction activities that they had never done before. Some participants mention activities related to the prevention of COVID-19 (guards, making masks, cleaning, personal hygiene, etc.) that can also be considered self -care and caring for other people.

Likewise, the participants also refer to creative activities linked to work and academic performance. Especially, those in the sample who identified themselves as teachers referred to creative activities related to the planning of teaching activities and the construction of digital educational resources. Students also indicate creative learning actions, such as technology-mediated group work, video making and online activities, etc.

During isolation, in addition to being "creative" in trying to carry out all the activities assigned (keep working remotely, help my children with homework, and invent activities to keep them entertained), I have given the task of transforming the old beach bicycle into a stationary bicycle to be able to carry out some physical activity. The most interesting thing is that, for this, I have had to use the tools and materials available in my house (Mario).

In sum, in their expressions, participants identify two larger types of creative activities developed in contexts of isolation, namely obligatory activities (work, academic and care) and leisure (crafts, performing arts, music, etc.) However, several of the activities, such as cooking, take place between duty and leisure. People identify creative actions in both types of activities; these actions demand alternative processes, especially due to the restrictions on resources, spaces, and possibilities imposed by isolation. Participants describe different actions and situations in which they develop creative processes. Most of the participants consider that the activities they mentioned are creative because they involve generation of an original action or product. Also, many participants say they have creatively resolved problems related to the invention of products with scarce resources. Improvised solutions, making adjustments and changes also define creative processes in isolation.

As Richards (2010) argues, creativity is a manifestation of originality in work and free time; it is not limited to artistic areas, but covers all activities of everyday life. Participants developed different creative actions in isolation; they correspond to those defined in other studies (non-isolation), such as daily creativity activities (Benedek et al., 2019; Eli- 
sondo \& Vargas, 2019). Other studies also point to handicrafts (Gandolfo \& Marty 2010; Pollanen, 2015) and dance (Arbillaga, Elisondo, \& Melgar, 2018) as creative actions that people develop in everyday life. Isolation imposes restrictions and possibilities for creativity. In this sense, creativity considerations as sociocultural processes that take place in certain contexts and according to the particularities of it take on special relevance (Corazza \& Glăveanu, 2020). Creativity is not a process that occurs in vacuum; contexts impose conditions and limitations. In the analyzed situation, social isolation imposes rules and limitations on processes, but also generates times, possibilities, and interactions that enhance production of creative actions and artifacts.

Not being prepared to work in virtual teaching activities (...) it is a (creative) challenge to produce activities that generate real learning in students (...). The work of the land, the skills to cultivate a small space, can be achieved in various ways. You have to combine them creatively to achieve some organic production. The situation of confinement leads us to develop survival strategies to share with the family. Imagination must be started to generate moments of interaction and satisfaction that enrich us in the conflictive external situation (Sonia).

Many participants assure that it is the first time that they carry out the activities described. In other words, isolation imposed limitations, but also created conditions for new challenges and activities. Several participants indicated interest in continuing these activities when routines return. Quarantine, the impossibility of leaving home, seems to have activated cognitive processes linked to creativity: search for alternatives, imagination, improvisation, problem solving, conceptual combination, etc. Some people discovered their interest in certain activities and others have retained pending interests. Distraction, imagination, entertainment, challenges seem to be engines of curiosity that acts as a strategy to face adverse situations.

\section{Alone, but not so Alone}

Most of the participants say that they carried out creative activities in solitude $(N=165)$. Others point out that they performed some activities in solitude and others in company, mainly with family members $(\mathrm{N}=55)$. Some individuals participated in activities alone at home, but in interactions with other persons through technological mediations $(N=40)$, for instance gym classes by ZOOM, academic activities with university colleagues, virtual classes, etc. Also, some participants defined as creative the social events developed with technological mediations: we celebrated a birthday on Skype, read a story to my nephew every night on Skype. 


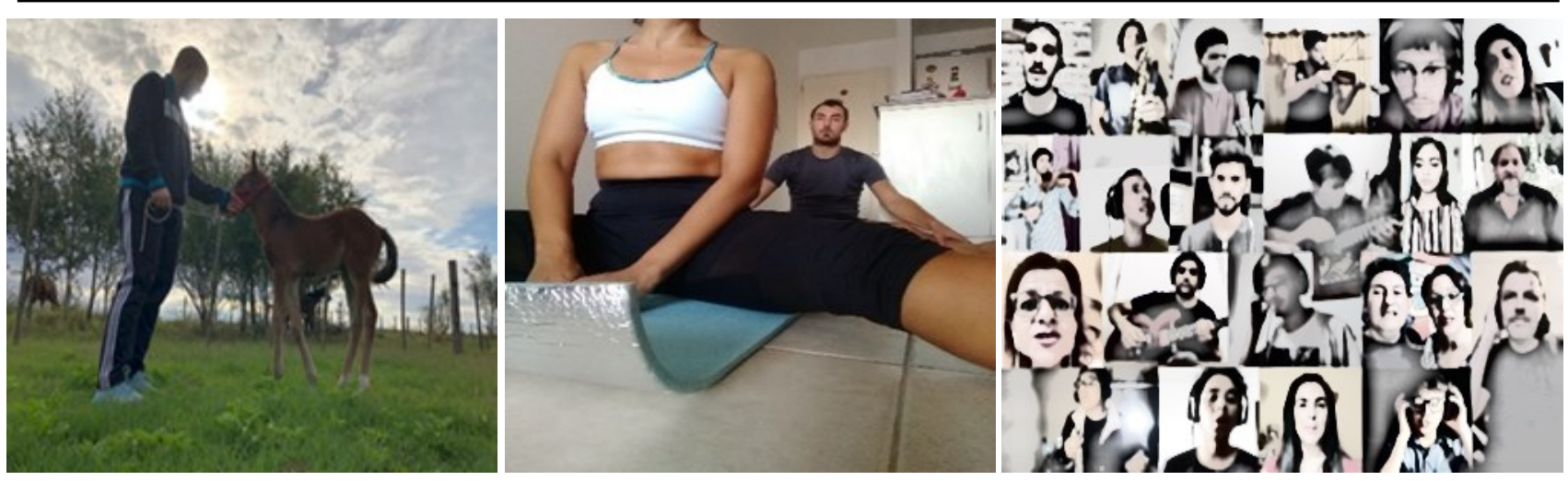

Figure 4. We are not alone. Source: images shared by participants

Although in some cases the creative processes are solitary, many times directly or indirectly they involve others. For example, many participants expressed that they cooked alone but that emerging products were shared with family and friends. Likewise, solitary production also implies the recognition of audiences, their interests, and particularities. People create alone but considering others as potential recipients of creative products. In sum, creative processes are always socio-cultural; they involve others, others can actively participate in the process or be audiences and receivers of the products. Likewise, creative processes are always developed based on knowledge built by someone else (Elisondo, 2016; Tanggaard, 2013). We agree with Modrzejewska-Świgulska (2018), who points out that creative process involve networks of relationships between different people and the creator. The final product built by the creator is generally the result of the interaction between individual work and collective work. The other people participate in the creative process assuming different roles: collaborators, evaluators, mentors, audiences, recipients of the products, etc. In this sense, creative potentials (Corazza \& Glăveanu, 2020) also depend on the networks of relationships available in the contexts that the creator inhabits.

In the particular case under analysis, isolation by COVID-19, individuals identifies some activities that they carried out in solitude and highlighted the importance of having that personal space and time. Other activities were shared physically (with people who live together) or virtually (mediated by technologies). In quarantine, technological devices expand the possibilities of interaction with groups, creating conditions to carry out certain creative group activities. One participant said that they have never performed the creative activities they mention with other people, especially with the family, such as creating games, choreography, songs, etc. In this sense, isolation seems to create conditions to develop new creative activities with other people. Many people participated in social events (parties, birthdays, etc.) mediated by technologies; these activities are novel and original. Isolation seems to have fostered creative processes aimed at generating spaces for interaction, celebration, and enjoyment with other people. In sum, isolation imposed by the pandemic has generated in some groups new interactions that can lead to creative 
actions and products. We highlight the importance of the strategies constructed by the participants to interact with other people during the quarantine, as argued by Brooks et al. (2020), Vinkers et al. (2020) and Stankovska et al. (2020). These actions prevent loneliness, boredom, and negative consequences of isolation on mental health.

\section{Being and Feeling in Isolation}

Most of the participants express positive emotions related to creative activities in isolation. They use the following words to define their emotional states: happiness, pleasure, joy, well-being, flow, energy (See Figure 5). There are also expressions such as "relaxed" and "relieved," which indicate a certain preventive and therapeutic nature of creative activities in quarantine. In addition, there are some negative emotions, especially those related to carrying out work activities remotely. Some participants expressed tension and anxiety about the new situations that are generated when trying to develop work activities from home. Creative activities seem to be linked with positive emotions and also as therapeutic activities that dismiss stress and anxiety in isolation. In this sense, we observe important positive impacts of creativity on people's mental health. Participant expressions are related to previous studies that indicate the impacts of creative activities on a general well-being of people (Richard, 2010) and the development of positive emotions (Benedek, Jauk, Kerschenbauer, Anderwald \& Grond, 2017; Conner et al. 2018; Karwowski et al., 2017; Silvia et al., 2014).

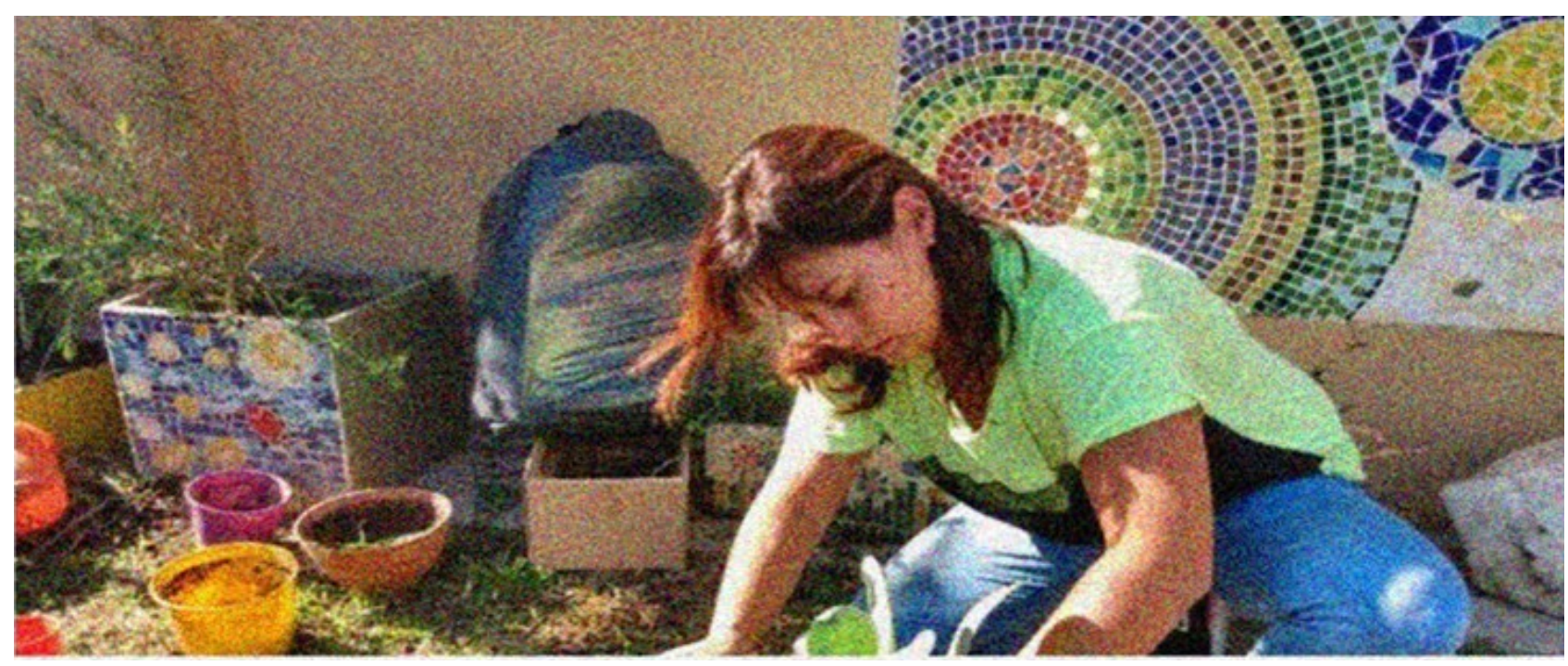

Figure 5. Being and feeling in isolation. Source: images sent by participants

Negative emotions are especially linked to duty and work tasks. In general, the activities that people perform for their own motivation generate positive emotions; those that are imposed generate some anxiety and negative emotions. Carrying out work activities from home, overlapping domestic and family tasks, difficulty of finding times and spaces for work, caused situations of anxiety, tension and discomfort in several of the interviewees. 
According to the participants, the development of creative activities during the quarantine enables spaces for personal expression, self-realization, growth and project development. In this sense, they contribute significantly to health, identity, and the possibilities of projecting future actions. Many of the interviewees expressed interest in continuing to develop creative activities after the quarantine. Deployment of creative processes in everyday contexts seems to be a promoter of health in a broad sense, since it fosters positive emotions related to personal expression, self-regulation, and self-realization. Previous studies of everyday creativity (Gandolfo \& Marty, 2010; McCabe, 2015; Pollanen, 2015) also point out the positive effects of creative activities in the processes of selfconfidence, self-esteem, and identity construction. Similarly, development of creative processes promotes autonomy, personal development, and communication with other people.

In what could be considered a paradox, several interviewees indicated feelings of freedom in the context of confinement. Expressions of those participants are interesting in that they indicate feeling free to carry out many activities that in "normal" contexts they could not do due to work obligations. Freedom seems not so linked to the possibility of going out, but to having time to do activities that are of interest to people.

Excellent. I think that this isolation due to the pandemic drives us to take advantage of time in things that we really want to do and that due to work and other obligations we could not. Having time makes me feel free (Rosa).

According to Vinkers et al. (2020) and Brooks et al. (2020), stress is normal in isolation. However, it is important that people generate the behavior of resilience that helps them perceive themselves as retaining some control over the situation. In this sense, construction of routines, healthy physical and nutritional practices, prevention and care strategies, and interactions with other people contribute positively to mental health in times of pandemic. Also, Stankovska et al. (2020) emphasize the need for an adequate organization of working times in isolation. Creativity as a possibility to build alternatives and novel products plays an important role in assuming control over adverse situations.

\section{Creativity, Motivations and Quarantine}

Participants indicate different motivations for developing creative activities in quarantine. As we defined in the previous category, most of them carry out the activities that generate pleasure, well-being, and joy. A significant number of participants have indicated that they develop creative activities, such as coping strategies and reduction of anxiety and tension caused by isolation and fear of COVID-19.

We have to try to do things that reassure us because the situation is really worrying and a little scary (...) then it is better to be busy with something we like (Carla). 
Many participants also developed creative activities in fields never explored before; a situation that generates challenges and tensions. The participants' statements also reveal social motivations related to sharing with others, especially with family members, and such prosocial motivations as creating strategies and artifacts oriented towards community well-being. Some participants say they develop creative activities as a way to stay active, have energy, and at the same time spend time entertaining.

Considering the classification used in the study by Benedek et al. (2019), in present research, motivations of enjoyment, expression, challenge, coping, social, and prosocial interaction predominate. Expressions referring to motivations related to recognition, materiality, and duty are not clearly observed. Perhaps in the case of virtual work activities, a certain motivation of duty can be inferred, although it cannot be inferred directly from the expressions of the participants. Most seem to develop creative activities to experience pleasure, to cope with stress, and to share with others. There are also motivations linked to the pandemic, such as elaboration of masks and community prevention strategies. In these cases, prosocial motivations are observed (See Figure 6). Staying busy and keeping your mind occupied are also expressions that appear in many of the interviewees and perhaps synthesize motivations of several participants in isolated contexts. The time dimension appears significantly in the analyses. Having time and at the same time doing things so that the time passes faster are often expressions that intersect between the voices of the participants. This, like the freedom in confinement, could be considered a creative paradox in context of COVID

Like Benedek et al. (2019), we also observed that the motives differ according to the creative activities developed. Cooking appears linked to social motivations to share with other people and enjoyment. Artistic activities, such as painting and music are linked to the desire for expression and the need to relieve tension. Physical activities, such as yoga, body expression and meditation, according to the participants, are activities that during the quarantine allowed us to reflect and get to know our own body, emotions, and personal needs. These activities would be motivated by desires for self-knowledge and personal expression. The care activities of other people are linked to social and prosocial motives that are oriented towards generation of objects and actions that promote wellbeing of others, both family members and the community in general. 

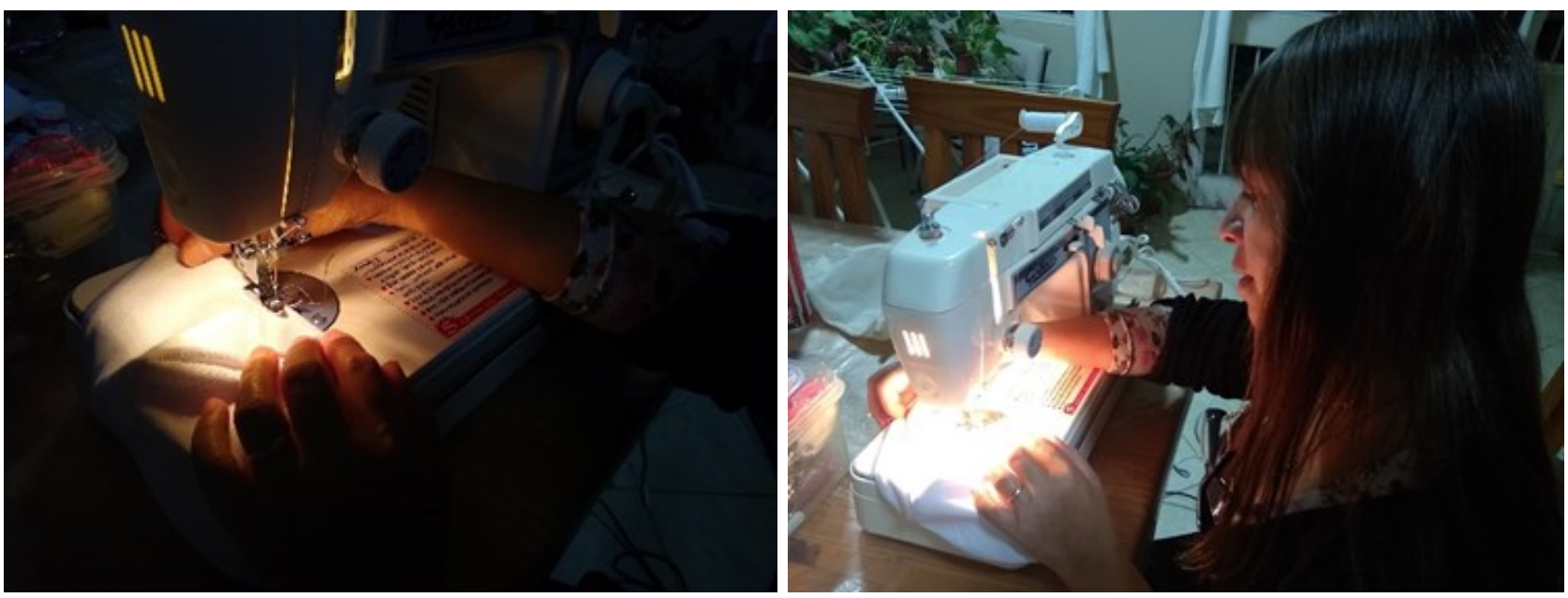

Figure 6. Creativity against the pandemic: elaboration of masks. Source: images sent by the participants

In agreement with specialists (Vinkers et al., 2020; Wang et al., 2020), we highlight the actions of self-care and care of other people, as initiatives that cause a lower psychological impact of depression, anxiety, and stress in times of pandemic. These creative actions contribute to the promotion of physical and mental health, generating resilient and solidary practices. According to Brooks et al. (2020), altruistic behaviors during isolation promote well-being and mental health. Stankovska et al. (2020) also point out the importance of community strategies of mutual support for coping disorders related to isolation.

\section{CONCLUSIONS}

Isolation has imposed substantive modifications on people's lives. Our results indicate that the majority of the participants developed various creative activities in quarantine; these activities generated positive emotions and allowed to face negative emotions linked to the pandemic. The motivations also varied, although the reasons linked to enjoyment, coping, and sharing with other people predominate.

When analyzing the relationships between creativity and isolation, apparent paradoxes emerge. Many of the activities involve novelty and challenges and were carried out for the first time, as expressed by the participants. In other words, the quarantine generated both the opportunity and the need to generate novel practices of leisure and work. Communication technology plays an important role when it comes to needs and opportunities emerging from confinement. The relationships between freedom and confinement also generate an apparent paradox, as many people feel free in isolation. This freedom seems to be mainly associated with availability of time to carry out activities that are of interest and could not be carried out before dure to pre-COVID routines. Perceptions of time are also paradoxical; participants value having time, but they also emphasize the need to do things to make time go faster. Free time appears as a possibility to do things but also generates a certain anxiety or emptiness that must be filled with activities. The 
context also generates certain paradoxes linked to emotions, even though positive emotions predominate; tension, discomfort, and stress are also present in participants' expressions. Emotions vary depending on activities. Negative emotions are especially linked to job obligations and the overlap between domestic care and work activities. Space and mobility also generate paradoxes in quarantine; people build creative strategies to move in confined spaces and also to generate numerous virtual ways of mobility: interactions with people, places and objects that are in remote spaces.

(...) we keep in touch with others through a variety of communication, virtual and digital technologies and enjoy the experience of being in other places and situations through movies, games, and online discussions. Above all, we engage in psychological forms of mobility, helped by our memory, imagination and creativity, and participate in a series of activities and scenarios we are being denied access to at the moment. (Glăveanu, 2020, p. 186)

The observed paradoxes are linked to specialist approaches regarding creative processes as a combination of apparently contradictory elements (Brillenburg Wurth, 2019; Stierand et al., 2019). Cropley (1997) points out paradoxes that characterize creative processes: interactions between personality traits, motivations, and social interests, convergent and divergent thoughts, specific and new knowledge, conscious and unconscious actions, etc. The author argues that creative processes are paradoxical in that they involve adhering to norms, and at the same time, they have a certain freedom to transgress them. Glăveanu (2019) also refers to the paradox of the immersion of creatives in their work together with the possibility of moving away from it to create something new. According to the author, the paradoxes between immersion and connectivity favor creative agency. In the data analyzed in the present study, the paradoxes between freedom, mobility and confinement, isolation and connectivity, seem to enhance creative processes in times of pandemic. Availability of time, scarcity of resources, contradictory emotions, obligation and leisure also configure creative paradoxes in isolation.

Everyday creative processes acquire particular characteristics in quarantine, where limitations regarding availability of resources and possibilities of interacting with other people prevail. However, these limitations seem to generate creative searches for alternatives to solve the problem. Likewise, isolation seems to generate, at least in the analyzed group, opportunities for self-knowledge, consolidation of family ties, generation of new care practices and search for healthier, more sustainable and environmentally friendly alternatives. In this sense, we observe resilient behaviors (Vinkers et al., 2020) that contribute to maintaining ties, routines, as well as self-care and care for others. Like the Forgeard's (2013) study, we found that in the face of adversity, people perceive crea- 
tive possibilities for personal growth. Likewise, difficulties also promote altruistic behaviors, as pointed out by Brooks, et al. (2020).

\section{Limitations and future research}

The present study presents limitations that make it impossible to generalize the results. The considerations made are pertinent only for the analyzed group and characterize its particularities. The sample includes participants of medium socio-economic level with availability of material and symbolic resources to face the situation. In other studies, it is necessary to consider vulnerable groups, which would allow more complex analyses regarding social inequalities and issues that isolation generates in contexts of unmet basic needs, as Johnson, Saletti-Cuesta, and Tumas (2020) point out. Likewise, it is necessary to clarify that the study was carried out in the initial moments of isolation, so there were no difficulties related to weariness, exhaustion, and stress generated by confinement. At that time, social and economic uncertainty did not appear as a concern for the participants. It is interesting in future studies to analyze the effects of post-quarantine and the impacts of isolation on the health and economy of different social groups. To understand the processes over time and in different contexts, longitudinal and comparative studies would be relevant. As a future line of research, it is proposed to analyze creative postpandemic processes and impacts on new economic and social enterprises.

\section{REFERENCES}

American Psychological Association's (2017). Ethical Principles of Psychologists and Code of Conduct. Retrieved from http://www.apa.org/ethics/code/ethics-code-2017.pdf Arbillaga, L., Elisondo, R. C., \& Melgar, M. F. (2018). Espacios que proyectan hacia nuevos horizontes. La danza como puente entre la creatividad y lo cotidiano. Estudios sobre Arte Actual, (6), 21-33.

Beghetto, R. A., Kaufman, J. C., \& Hatcher, R. (2016). Applying creativity research to cooking. The Journal of Creative Behavior, 50 (3), 171-177. https://doi.org/10.1002/ jocb. 124

Benedek, M., Bruckdorfer, R., \& Jauk, E. (2019). Motives for Creativity: Exploring the what and why of everyday creativity. The Journal of Creative Behavior, 0 (0) 1-16. https://doi.org/10.1002/jocb.39

Benedek, M., Jauk, E., Kerschenbauer, K., Anderwald, R., \& Grond, L. (2017). Creating art: An experience sampling study in the domain of moving image art. Psychology of Aesthetics, Creativity, and the Arts, 11, 325-334. https://doi.org/10.1037/aca0000102

Brillenburg Wurth, K. (2019). The Creativity Paradox: An Introductory Essay. The Journal of Creative Behavior, 53(2), 127-132. https://doi.org/10.1002/jocb.231 
Brooks, S., Webster, R., Smith, L., Woodland, L., Wessely S., Greenberg, N., \& Rubin, G. (2020). The psychological impact of quarantine and how to reduce it: rapid review of the evidence. Lancet, 395, 912-920. https://doi.org/10.1016/S0140-6736(20)30460-8

Conner, T. S., \& Silvia, P. J. (2015). Creative days: A daily diary study of emotion, personality, and everyday creativity. Psychology of Aesthetics, Creativity, and the Arts, 9, 463-470. https://doi.org/10.1037/aca0000022

Conner, T. S., DeYoung, C. G., \& Silvia, P. J. (2018). Everyday creative activity as a path to flourishing. The Journal of Positive Psychology, 13, 181-189. https://doi.org/10.108 0/17439760.2016.1257049

Corazza, G. (2017) Organic Creativity for Well-Being in the Post-Information Society. Europe's Journal of Psychology, 13(4), 599-605. https://doi.org/10.5964/ ejop.v13i4.154714

Corazza, G. \& Glăveanu, V. (2020) Potential in Creativity: Individual, Social, Material Perspectives, and a Dynamic Integrative Framework. Creativity Research Journal, 32 (1), 81-91. https://doi.org/10.1080/10400419.2020.1712161

Cotter, K. N., \& Silvia, P. J. Ecological assessment in research on aesthetics, creativity, and the arts: Basic concepts, common questions, and gentle warnings. Psychology of Aesthetics, Creativity, and the Arts, 13(2), 211-217. https://doi.org/10.1037/ aca0000218

Cropley, A. J. (1997). Creativity: A bundle of paradoxes. Gifted and Talented International, 12, 9-15. http://dx.doi.org/10.1080/15332276.1997.11672859

Elisondo, R. (2016). Creativity is always a social process. Creativity. Theories-ResearchApplications, 3(2), 194-210.

Elisondo, R. C., \& Vargas, A. (2019). Women's Everyday Creative Activities: a Qualitative Study. Creativity. Theories-Research-Applications, 6(1), 91-111.

Fancourt, D., Garnett, C., \& Müllensiefen, D. (2020, January 13). The relationship between demographics, behavioral and experiential engagement factors, and the use of artistic creative activities to regulate emotions. Psychology of Aesthetics, Creativity, and the Arts. Advance online publication. http://dx.doi.org/10.1037/aca0000296

Forgeard, M. J. C. (2013). Perceiving benefits after adversity: The relationship between self-reported posttraumatic growth and creativity. Psychology of Aesthetics, Creativity, and the Arts, 7(3), 245-264. https://doi.org/10.1037/a0031223

Gandolfo, E., \& Grace, M. (2010). Women doing it forever: The everyday creativity of women craftmakers. Australian and New Zealand Journal of Art Therapy (ANZJAT), 5(1), 29-43. Retrieved from http://vuir.vu.edu.au/15967/1/15967.pdf 
Gfeller, F. (2019). Changing one's foodway: Creativity as repositioning. In The Palgrave Handbook of Social Creativity Research (pp. 335-352). Palgrave Macmillan, Cham.

Glăveanu, V. P., Hanchett Hanson, M., Baer, J., Barbot, B., Clapp, E. P., Corazza, G. E., \& Montuori, A. (2020). Advancing creativity theory and research: A socio-cultural manifesto. The Journal of Creative Behavior, 54(3), 741-745.

Glăveanu, V. P. (2020). New Mobilities and Psychology: Why are We Still Not on the Move?. Europe's Journal of Psychology, 16(2), 186-192. https://doi.org/10.5964/ ejop.v16i2.3117

Glăveanu, V. P. (2019). Epilogue: Creativity as immersed detachment. The Journal of Creative Behavior, 53(2), 189-192. https://doi.org/10.1002/jocb.242

Glăveanu, V.P., Hanchett Hanson, M., Baer, J., Barbot, B., Clapp, E., Corazza, G.E. \& Sternberg, R. (2019). Advancing creativity theory and research: A sociocultural manifesto. Journal of Creative Behavior. 54(3), 741-745 https://doi.org/10.1002/jocb.395 Glăveanu, V. \& Sierra, Z. (2015) Creativity and epistemologies of the South. Culture \& Psychology, 21(3), 340-358. https://doi.org/10.1177/1354067X15601196

Johnson, M.C., Saletti-Cuesta, L., \& Tumas, N. (2020). Emociones, preocupacionesy reflexiones frente a la pandemia del COVID-19 en Argentina. Ciência \& Saúde Coletiva, 25, 2447-2456. https://doi.org/10.1590/1413-81232020256.1.10472020

Karwowski, M., Lebuda, I., Szumski, G., \& Firkowska-Mankiewicz, A. (2017). From momentto-moment to day-to-day: Experience sampling and diary investigations in adults' everyday creativity. Psychology of Aesthetics, Creativity, and the Arts, 11, 309-324. https://doi.org/10.1037/aca0000127

Kaufman, J. C., \& Beghetto, R. A. (2009). Beyond big and little: The four c model of creativity. Review of general psychology, 13(1), 1-12. https://doi.org/10.1037/a0013688

Li, S., Wan, Y., Xue, J., Zhao, N., \& Zhu, T. (2020). The Impact of COVID-19 Epidemic Declaration on Psychological Consequences: A Study on Active Weibo Users. International Journal of Environmental Research and Public Health, 17(6), 2032. https:// doi.org/10.3390/ijerph17062032

McCabe, M., \& de Waal Malefyt, T. (2015). Creativity and cooking: Motherhood, agency and social change in everyday life. Journal of Consumer Culture, 15(1), 48-65. https:// doi.org/10.1177/1469540513493202

Modrzejewska-Świgulska, M. (2018). Professional Competences. Reconstruction of the Opinions of Polish Female Directors. Creativity. Theories-Research-Applications, 5(1), 72-83. https://doi.org/10.1515/ctra-2018-0005 
Official Gazette of the Argentine Republic (2020). Mandatory and Preventive Social Isolation. Decree 297/2020. Retrieved from https://www.boletinoficial.gob.ar/detalleAviso/ primera/227042/20200320

Pöllänen, S. (2015). Elements of crafts that enhance well-being: Textile craft makers' descriptions of their leisure activity. Journal of Leisure Research, 47(1), 58-78. https:// doi.org/10.1080/00222216.2015.11950351

Richards, R. (2010). Everyday creativity. In J. C. Kaufman \& Sternberg, R. J. (Eds.). The Cambridge handbook of creativity. (pp. 189-215). Cambridge: Cambridge University Press.

Shigemura, J., Ursano, R. J., Morganstein, J. C., Kurosawa, M., \& Benedek, D. M. (2020).Public responses to the novel 2019 coronavirus (2019-nCoV) in Japan: Mental health consequences and target populations. Psychiatry and Clinical Neurosciences (Advance online publication). https://doi.org/10.1111/pcn.12988

Silvia, P. J., Beaty, R. E., Nusbaum, E. C., Eddington, K. M., Levin-Aspenson, H., \& Kwapil, T. R. (2014). Everyday creativity in daily life: An experience-sampling study of "little c" creativity. Psychology of Aesthetics, Creativity, and the Arts, 8(2), 183-188. https://doi.org/10.1037/a0035722

Stankovska, G., Memedi, I., Dimitrovski, D. (2020). Coronavirus COVID-19 Disease, mental Health and Psychosocial Support. Society Register, 4(2), 33-48. https:// doi.org/10.14746/sr.2020.4.2.03

Stierand, M., Boje, D. M., Glăveanu, V., Dörfler, V., Haley, U. C., \& Feuls, M. (2019). Paradoxes of "creativity": Examining the creative process through an antenarrative lens. The Journal of Creative Behavior, 53(2), 165-170. https://doi.org/10.1002/jocb.224

Tan, C. S., Lau, X. S., Kung, Y. T., \& Kailsan, R. A. L. (2019). Openness to experience enhances creativity: The mediating role of intrinsic motivation and the creative process engagement. The Journal of Creative Behavior, 53(1), 109-119. https://doi.org/10.1002/jocb.170

Tanggaard, L. (2013). The sociomateriality of creativity in everyday life. Culture \& Psychology, 19(1), 20-32. https://doi.org/10.1177/1354067X12464987

Torales, J., O'Higgins, M., Castaldelli-Maia, J. M., \& Ventriglio, A. (2020). The outbreak of COVID-19 coronavirus and its impact on global mental health. International Journal of Social Psychiatry, 31(Advance online publication) https://doi.org/10.1177/0020764020915212

Vinkers, C. H., van Amelsvoort, T., Bisson, J. I., Branchi, I., Cryan, J. F., Domschke, K., \& van der Wee, N. (2020). Stress resilience during the coronavirus pandemic. European Neuropsychopharmacology, 35, 12-16 https://doi.org/10.1016/j.euroneuro.2020.05.003 
Wang, C., Pan, R., Wan, X., Tan, Y., Xu, L., Ho, C.S., \& Ho, R.C. (2020). Immediate Psychological Responses and Associated Factors during the Initial Stage of the 2019 Coronavirus Disease (COVID-19) Epidemic among the General Population in China. International Journal of Environmental Research and Public Health, 17, 1729-1754 . https://doi.org/10.3390/ijerph17051729

World Health Organization (2020) Update of the strategy in front to COVID-19. Retrieved from https://www.who.int/docs/default-source/coronaviruse/covid-strategy-update14april2020_es.pdf?sfvrsn=86c0929d_10

Corresponding author at: Romina Cecilia Elisondo, Universidad National de Río Cuarto, Ruta 36 Km 601, Río Cuarto Cordoba Argentina 5800

E-mail: relisondo@gmail.com 